\title{
Changing trend of HIV seroprevalence among antenatal women at tertiary care hospital in north-west Rajasthan, India, 10 years retrospective study
}

\author{
Parul Prakash, Preeti Sankhala
}

\author{
Corresponding author: Dr Parul Prakash, Associate Professor, Department of Obstetrics and \\ Gynaecology, Sardar Patel Medical College, Bikaner, Rajasthan, India; Email - \\ parulprakash@ymail.com
}

Distributed under Attribution-Non Commercial - Share Alike 4.0 International (CC BY-NC-SA 4.0)

\begin{abstract}
Objectives: The aim of the study was to analyze the changing trends of seroprevalence among antenatal women in last 10 years at Sardar Patel Medical College, Bikaner, Rajasthan. Materials and methods: Retrospective study; cross-sectional in design; carried out through the analysis of data collected from PPTCT centre, S.P. Medical College, Bikaner (Rajasthan). The study included all the pregnant women of PPTCT centre from April 2009 to March 2019. Results: A total of 154487 antenatal women were registered for period of approximately 10 years from April 2009 to March 2019 in this study. Out of these 111461(72.15\%) women were ready for testing after counselling. Overall 44 women were found seropositive for HIV-I antibodies with a seroprevalence rate of $0.04 \%$. Most of them were multigravida (59.1\%), seropositive women, majority $(57.1 \%)$ were in age group of 21 to 25 years. The HIV seroprevalence rate was ranging between $0.05 \%$ in $2009-10$ to $0.07 \%$ in $2018-19$. Conclusion: Seroprevalence of HIV infection among antenatal women was on an average $0.04 \%$ in the past 10 years. There was variation in incidence of seropositive women over last 10 years with its peak of $0.07 \%$ in $2018-19$. The rising trend of incidence can be decreased in antenatal women by public awareness programme and implementation of mandatory detailed history, counselling and testing of HIV by joint efforts of public and private sector.
\end{abstract}

Keywords: Seroprevalence, PPTCT, NACO.

HIV/AIDS is spreading worldwide at an alarming rate. The first AIDS case was reported in 1986 in India and India is categorized as a low prevalence nation for HIV with seroprevalence rate of less than $1 \%$ among adult population. India has third largest number of estimated people living with HIV/AIDS in the world. There are an estimated 21.17 lakhs people living with HIV/AIDS of which $6.54 \%$ are children ( $<15$ years) with an adult prevalence of $0.26 \%$ in $2015^{1}$. The incidence of infection especially in sexually active group is the most sensitive marker to track the course of HIV epidemic. Unfortunately, incidence is hard to measure, but prevalence in young women is indirect but useful tool ${ }^{2}$. Accordingly, HIV data from antenatal women has been used to monitor trend in the general population and to predict seroprevalence in young children (Table 1$)^{3,4}$. The predominant mode of HIV transmission is through hetero sexual contact, therefore women are at high risk of getting infection ${ }^{5}$. The transmission of HIV from infected mother to infant ranges from $25 \%$ - $35 \%$ which accounts for $4 \%$ of the total HIV infection in India ${ }^{6}$. Hence, mother to child

Received: $3^{\text {rd }}$ December 2019. Accepted: $11^{\text {th }}$ January 2020.

Prakash P, Sankhala P. Changing trend of HIV seroprevalence among antenatal women at tertiary care hospital in north-west Rajasthan, India, 10 years retrospective study. The New Indian Journal of OBGYN. 2020; 7(1): 71-5. 
transmission is by far the most significant route of transmission of HIV infection in children below the age of

Table 1: According to NACO (16-17) India statistics

\begin{tabular}{ll}
\hline Estimated pregnant women & $3,00,33,000.00$ \\
Estimated PPTCT need & $33,673.00$ \\
Pregnant women tested for HIV & $1,68,31,201.00$ \\
HIV Positive among pregnant women (\%) & 0.05 \\
Coverage for HIV testing of pregnant women (\%) & 56.00
\end{tabular}

Following the guidelines of NACO, the counsellor of the PPTCT centre interviewed the pregnant women under strict confidentiality. After pre-test counselling and obtaining consent from them, blood samples were collected. HIV antibodies were tested by the three rapid tests protocol as per the guidelines laid down by the World Health Organization (WHO testing strategy III) and the testing policy of NACO, Government of India (NACO, 2007).

15 years ${ }^{7}$. So in NACP phase III (2007-2012), prevention of parent to child transmission (PPTCT) has been given due importance. As HIV infections in women occur primarily during their reproductive years, pregnancy provides a unique opportunity for implementing HIV infection prevention strategies in women. The incidence of HIV infections, especially in sexually active young people is the most sensitive marker to track the course of HIV epidemic.

Prevention of parent to child transmission of HIV

Samples tested reactive in the first method were subjected to tests with two different rapid tests, the samples were considered as positive when found reactive by all three different methods.

\section{Results}

A total of 154487 antenatal women registered in department of Obstetrics \& Gynecology, S.P. Medical College Bikaner, Rajasthan, India for period of approximately 10 years from April 2009 to March 2019 were (PPTCT) program has been launched under the NACP in year $2002^{8,9}$. HIV sentinel surveillance (HSS), data from the pregnant women at antenatal clinics shows considerable difference continue to exist in the prevalence rates across different geographical region of India. Hence, this study was planned to determine the prevalence of HIV infection in pregnant women of a Tertiary Care Hospital, Akola India.

\section{Materials and methods}

Retrospective hospital record based descriptive study; cross-sectional in design; carried out through the analysis of secondary data collected from PPTCT centre, S.P. Medical College, Bikaner (Rajasthan). The study included all the pregnant women of PPTCT centre from April 2009 to March 2019. Pregnant women registered at the antenatal clinics of this hospital are routinely advised to undergo HIV screening after pre-test counselling and informed consent. All the essential information was collected from the pregnant women by interviewing them. The variables studied included age, marital status, occupation etc.
Table 2: Total ANC women counseled and tested at PPTCT from 20092019

\begin{tabular}{llll}
\hline $\begin{array}{l}\text { Total no. of } \\
\text { ANC counseled }\end{array}$ & $\begin{array}{l}\text { Total no. of } \\
\text { ANC tested (\%) }\end{array}$ & $\begin{array}{l}\text { Total no. of } \\
\text { HIV positive }\end{array}$ & $\begin{array}{l}\text { Percentage (\%) of } \\
\text { seropositivity }\end{array}$ \\
\hline 154487 & $111461(72.15 \%)$ & 44 & $0.04 \%$ \\
\hline
\end{tabular}

Table 3: Demographic characteristics of seropositive antenatal women $(\mathrm{N}=44)$

\begin{tabular}{llll}
\hline Demographic characteristics & No. of seropositive & Percentage (\%) \\
\hline \multirow{2}{*}{ Marital status } & Married & 44 & 100 \\
& Unmarried & 0 & - \\
\hline \multirow{2}{*}{ Religion } & Hindu & 41 & 93.2 \\
& Muslims & 6 & 6.8 \\
& Others & 0 & - \\
\hline \multirow{2}{*}{ Residence } & Rural & 13 & 29.6 \\
& Urban & 31 & 70.4 \\
\hline \multirow{3}{*}{ Occupation } & Illiterate & 16 & 36.4 \\
& Primary & 20 & 45.4 \\
& Secondary & 4 & 9.1 \\
& Graduate & 4 & 9.1 \\
\hline \multirow{2}{*}{ Gravidity } & Housewife & 42 & 95.5 \\
& Labourer & 2 & 4.5 \\
\hline \multirow{3}{*}{ Husband status } & Service & 0 & - \\
& Primi & 18 & 40.9 \\
& Multi & 26 & 59.1 \\
\hline & Reactive & 29 & 65.9 \\
& Non Reactive & 10 & 22.7 \\
& Not Known & 5 & 11.4 \\
\hline
\end{tabular}


The New Indian Journal of OBGYN. 2020 (July-December); 7(1)

included in this study. Out of these 111461 (72.15\%) women were ready for testing after counseling. Overall 44 women were found to be seropositive for HIV-I antibodies with a seroprevalence rate of $0.04 \%$ (Table 2). All pregnant females were married and majority of them were Hindu (93.2\%) by religion, from urban area $(70.4 \%)$, studied up to primary $(45.4 \%)$ or secondary $(9.1 \%)$. Most of them were multigravida (59.1\%), housewife by occupation (95.5\%) and husbands of $65.9 \%$ seropositive women were found reactive (Table 3).

Table 4: Prevalence of seropositive women according to age $(\mathrm{N}=44)$

\begin{tabular}{lll}
\hline $\begin{array}{l}\text { Age group } \\
\text { (years) }\end{array}$ & $\begin{array}{l}\text { Number of } \\
\text { seropositive }\end{array}$ & $\begin{array}{l}\text { Percentage } \\
\%\end{array}$ \\
\hline $15-20$ & 8 & 18.2 \\
$21-25$ & 24 & 57.1 \\
$26-30$ & 9 & 20.5 \\
$31-35$ & 2 & 4.5 \\
$36-40$ & 1 & 2.3 \\
\hline
\end{tabular}

\section{Discussion}

This retrospective study represents that the overall HIV seroprevalence among antenatal women for past ten years was $0.04 \%$ and total HIV testing in last 10 years by opt out approach was $72.15 \%$. In opt out approach, pregnant women are told that an HIV test will be included in the standard group of prenatal tests and they may decline the test. Center for disease control (CDC) also recommends opt out approach as the testing rate is $85-98 \%{ }^{10}$.

According to the studies done by Parameshwari et al, Joshi et al, Sinha et al, Chaudhari et al and Dash et al; the acceptance of HIV testing by opt out approach was $100 \%$, $83 \%, \quad 79 \%, \quad 96 \%$ and $84 \%$ respectively ${ }^{7,11,12-14}$. This emphasizes that by good HIV counseling acceptance rate can increase up to $100 \%$ as highest testing rate in present study is in 2011-12 (98.1\%).

We observed that all seropositive women were married (100\%), majority of them were Hindu by religion $(93.2 \%)$, resident of urban areas $(70.4 \%)$, housewife by occupation $(95.5 \%)$ which is comparable to the study done by Dash et

Table 5: Year wise prevalence rate of $\mathrm{HIV}$ in antenatal women

\begin{tabular}{lllll}
\hline Years & $\begin{array}{l}\text { Total ANC } \\
\text { counseling }\end{array}$ & $\begin{array}{l}\text { Total ANC } \\
\text { testing (\%) }\end{array}$ & $\begin{array}{l}\text { ANC HIV } \\
\text { positive }\end{array}$ & $\begin{array}{l}\text { ANC HIV } \\
\text { positivity (\%) }\end{array}$ \\
\hline $2009-10$ & 13283 & $10529(79.3)$ & 5 & 0.05 \\
$2010-11$ & 13083 & $10220(78.1)$ & 4 & 0.04 \\
$2011-12$ & 15926 & $15627(98.1)$ & 6 & 0.04 \\
$2012-13$ & 16606 & $9835(59.2)$ & 6 & 0.06 \\
$2013-14$ & 16473 & $13297(80.7)$ & 1 & 0.01 \\
$2014-15$ & 15989 & $11828(74.0)$ & 4 & 0.03 \\
$2015-16$ & 17243 & $6743(39.1)$ & 1 & 0.01 \\
$2016-17$ & 15881 & $10660(67.1)$ & 3 & 0.03 \\
$2017-18$ & 15210 & $10898(71.7)$ & 6 & 0.06 \\
$2018-19$ & 14793 & $11824(79.9)$ & 8 & 0.07 \\
\hline
\end{tabular}

Amongst seropositive women, majority (57.1\%) were in age group of 21 to 25 years followed by the age group of 26 to 30 years $(20.5 \%)$ and 8 women $(18.2 \%)$ below 20 years of age were found seropositive (Table 4). A year wise analysis depicts that in 2009-10 10529 pregnant women tested for HIV and 5(0.05\%) patients were found to be seropositive. The HIV seroprevalence rates ranging between $0.05 \%$ in 2009-10 to $0.07 \%$ in $2018-19$. Prevalence of HIV in antenatal women was highest in 2018-19 followed by 2017 18 and $2012-13$ i.e. $0.07,0.06 \%$ \& $0.06 \%$ respectively. Lowest prevalence was noted in 2013-14 and 2015-16 i.e., $0.01 \%$ each (Table 5) and trend of HIV seroprevalence over a period of ten years. al, in which most of the women were married (99.05\%), Hindu by religion $(96.2 \%)$ and $87.6 \%$ women were housewife by occupation ${ }^{14}$. According to present study majority of the women were multigravida $(59.1 \%)$ in contrast to study done by Dash et al and Patil et al where most of the women were primigravida ${ }^{14,15}$.

In present study husbands of $29(65.9 \%)$ females were found positive and 10 (22.7\%) were negative for HIV infection. Status was not known of 5 husbands. Hence main route of transmission of infection was heterosexual contact. Higher percentage of husbands were found seropositive (96.59\%) in a study done by Ukey et al and less number of husbands were seroreactive ( $44 \%$ ) in another study done by Malik et al 16,17 . The age wise distribution showed a higher predisposition of infection in young age group 21-25 years (57.1\%) followed by $26-30$ years $(20.5 \%)$, and least in $36-40$ years $(2.3 \%)$. It may be because of the fact that 20 to 30 years is the most sexually active age group. High prevalence in this group can be an alarming sign as there is more chance of spread of infection and loss of youth may cause both social and financial burden for the nation. This also suggests that there was a higher awareness about HIV among married women of younger age group. Even Palikadavath et al 
showed that HIV awareness among North Indian married women was higher in 15-24 years age group as compared to older women $^{18}$.

While analysing the trend, we detected a rise in the HIV seroprevalence rate from $0.04 \%$ in $2010-11$ to 0.06 in 2012 13 and increased upto $0.07 \%$ in $2018-19$, the increasing trend is of great concern. Similarly, in study done by Gupta et al, a rise in the HIV seroprevalence rate from $0.7 \%$ in $2003-2004$ to $0.9 \%$ in $2005-2006$ was found ${ }^{19}$.

\section{Conclusion}

Seroprevalence of HIV infection among antenatal women was on an average $0.04 \%$ in the past 10 years. There was variation in incidence of seropositive women over last 10 years with its peak of $0.07 \%$ in 2018-19. This study being a hospital based study with limited sample size so this study is not true representative of entire North-West India but definitely provides a glimpse of present situation. Seroprevalence of antenatal women can be decreased by public awareness programme and implementation of mandatory detailed history, counseling and testing of HIV by joint efforts of public and private sector. Pregnancy provides best time for screening and implementation of PMTCT programme.

\section{Conflict of interest: None. Disclaimer: Nil.}

\section{References}

1. National AIDS Control Organization (NACO). Annual Report 2015-16. New Delhi: Department of health and Family welfare (Government of India); 2016. Available from: http://www.nacoonline.org.

2. Kumar R, Jha P, Arora P, Mony P, Bhatia P, Millson P, et al. Trends in HIV-1 in young adults in South India from 2000 to 2004. A prevelance study. Lancet. 2006; 367(9517): 1164-72.

3. Zaba B, Boerma T, White R. Monitoring the AIDS epidemic using HIV prevalence data among young women attending antenatal clinics: Prospects and problems. AIDS. 2000;14:1633-45.

4. Boerma JT, Ghys PD, Walker N. Estimates of HIV-1 prevalence from national population based surveys as a new gold standard. Lancet. 2003;362:1929-31.

5. Srikanth P, John TJ, Jeyakumari H, Babu PG, Mathai D, Jacob M, et al. Epidemiological features of acquired immunodeficiency syndrome in Southern India. Indian J Med Res. 1997;105:191-7.
6. Indian Council of Medical Research. Technical reportIndia HIV estimates- 2006. New Delhi: ICMR; 2006.

7. Parmeshwari S, Jacob MS, Vijayakumari JJ, Shalini D, Sushi MK, Shiv MR. A programme on prevention of mother to child transmission of HIV at government hospital at Tiruchengode Taluka, Namakkal District. Indian J Commun Med. 2009; 34: 261-3.

8. Ashtgi G, Metgud C, Walvekar P, Naik V. Prevalence of HIV among Rural Pregnant Women Attending PPTCT Services at KLE Hospital, Belgaum. AJMS. 2011; 4(1): 45-8.

9. Sarkate P, Paranjpe S, Ingole N, Mehta P. Monitoring HIV Epidemic in Pregnant Women: Are the Current Measures Enough? J Sex Transm Dis. 2015; 2015:194831.

10. Chaudhuri S, Bose S, Talukdar A, Ghosh US. Seroprevalence and utilization of therapeutic intervention in PPTCT services in a teaching hospital in Kolkata. J Obstet Gynecol India. 2007;57:251-6.

11. Joshi U, Kadri A, Bhojiya S. Prevention of parent to child transmission services and interventions- coverage and utilization: A cohort analysis in Gujarat, India. Indian J Sex Transm Dis. 2010; 31(2): 92-8.

12. Sinha A, Roy M. An ICMR task force study of Prevention of parent to child transmission (PPTCT) service delivery in India. Indian J Public Health. 2008;52:200-2.

13. Chaudhary S, Mundle M, Konar H, Das C, Talukdar A, Ghosh US. Utilization of therapeutic intervention to prevent mother to child transmission of HIV in a teaching hospital in Kolkata. Indian J Obstet Gynecol Res. 2010; 36: 619- 25.

14. Dash M, Mohanty I, Sahu S, Narasimham M, Padhi S, Panda P. Declining HIV seroprevalance among pregnant women in South Odisha, India: A six and half years tertiary care hospital based study. Int $\mathrm{J}$ Biomed Adv Res. 2012; 3(7): 546-51.

15. Patil VM, Moray AP, Patil SP. Ten years trend of HIV seroprevalence among Indian pregnant women attending antenatal clinic at tertiary hospital in Dhule, Maharashtra, India. Int $\mathrm{J}$ Reprod Contracept Obstet Gynecol. 2016; 5(5):1514-19.

16. Ukey PM, Akulwar SL, Powar RM. Seroprevalence of Human immunodeficiency virus infection in pregnancy in a tertiary care hospital. Indian J Med Sci. 2005; 59: 382-7. 
The New Indian Journal of OBGYN. 2020 (July-December); 7(1)

17. Malik A, Sami H, Khan PA, Fatima N, Siddiqui M. Prevalence of human immunodeficiency virus infection in Pregnant women and birth outcome at Tertiary Care Centre in a North Indian town. J Immunol Vaccine Tech. 2015;1(1):104.

18. Pallikadavath S, Jayachandran AA, Stones RW. Women's Reproductive Health, Socio cultural context and AIDS knowledge in Northern India. J Health Manag. 2005; 7(1):109-28.
19. Gupta S, Gupta R, Singh S. Seroprevalence of HIV in pregnant women in North India. BMC Infectious diseases. 2007;7:133.

Parul Prakash ${ }^{1}$, Preeti Sankhala ${ }^{2}$

${ }^{1}$ Associate Professor; ${ }^{2}$ Senior Resident, Department of Obstetrics and Gynaecology, Sardar Patel Medical College, Bikaner, Rajasthan, India. 